\title{
Anatomic Parameters of the Left Coronary Artery: an Angiographic Study in a South African Population
}

\author{
Parámetros Anatómicos de la Arteria Coronaria Izquierda: \\ Estudio Angiográfico en una Población Sudafricana
}

N. O. Ajayi"; L. Lazarus*; E. A. Vanker** \& K. S. Satyapal*

AJAYI, N. O.; LAZARUS, L.; VANKER, E. A. \& SATYAPAL, K. S. Anatomic parameters of the left coronary artery: an angiographic study in a South African population. Int. J. Morphol., 31(4):1393-1398, 2013.

SUMMARY: An understanding of the left coronary artery (LCA) anatomy is important for accurate diagnosis and therapeutic intervention in the management of coronary arterial diseases. This angiographic study aims to document the parameters of the LCA that may be of importance in the diagnosis and treatment of coronary artery diseases. An analysis of 151 coronary angiograms obtained from the cardiac catheterization laboratory in the eThekwini Municipality area of KwaZulu-Natal, South Africa was performed. The mean length and diameter of the LCA were 10.4 $\pm 4.1 \mathrm{~mm}$ (range 2.8-23.9 mm) and 3.8 $\pm 0.8 \mathrm{~mm}$ (range 2.1-6.5 mm), respectively. The mean angle of division between the two main branches was $86.2^{\circ} \pm 26.1^{\circ}$ (range $27^{\circ}-68.5^{\circ}$ ). There was a positive correlation between the length and the angle of division of the LCA, with the longest LCAs having the largest angle of division. The branching patterns of the LCA were $80.8 \%, 18.5 \%$ and $0.7 \%$ for bifurcation, trifurcation and quadrifurcation, respectively. Coronary arterial dominance was $81.5 \%, 15.2 \%$, and $3.3 \%$ for right, left, and co-dominance, respectively. This study corroborated earlier findings that the longer the length, the wider the angle of LCA division. A wide angle of LCA division, the shape and disposition of the proximal tract of LCA branches may affect flow, interfere with proper deployment of stents or may predispose to earlier atherosclerotic lesions.

KEY WORDS: Coronary arteries; Left coronary artery; Morphology; Morphometry; Coronary dominance.

\section{INTRODUCTION}

The length of the left coronary artery (LCA) extends from its origin at the aortic sinus to its division into its terminal branches. The course of the LCA is rarely longer than 2 $\mathrm{cm}$ in the adult, after which it divides into the circumflex $(\mathrm{Cx})$ and anterior interventricular artery (AIA) branches (Loukas et al., 2009). The study of LCA anatomy and its variation has been a subject of interest amongst several investigators (Fox et al., 1973; Gazetopoulos et al., 1976a; Saltissi et al., 1979; Muriago et al., 1997; Vilallonga, 2003; Reig \& Petit, 2004; Loukas et al.; Fazliogullari et al., 2010). The understanding of the LCA anatomy is an issue of clinical importance due to the extensive use of radiographic images for diagnostic and interventional purposes. In addition, it is useful in the development of non-invasive treatment and surgical intervention for coronary arterial diseases (Reig \& Petit).

There is great variability in the dimensions of the coronary arteries in the normal population (Saikrishna et al.,
2006). The size of coronary vessels are influenced by factors such as age, sex, body weight, body surface area, weight of the heart and ethnicity/race (Leung et al., 1991; Dodge et al., 1992; Lip et al., 1999). The definition of the severity of coronary arterial narrowing depends on proper knowledge of the range of the normal size of the coronary arterial tree (Vieweg et al., 1976).

Prior to the middle of the $20^{\text {th }}$ century, there was lack of adequate description of the caliber of normal coronary arteries. Several studies were later conducted with reports on the size of coronary arteries. In the management of coronary artery disease, the size of the coronary artery usually determines the treatment options and smaller arteries affects outcome in procedures such as balloon angioplasty and stenting, and may cause anastomotic difficulties during bypass grafting (Zindrou et al., 2006).

\footnotetext{
* Department of Clinical Anatomy, School of Laboratory Medicine and Medical Sciences, College of Health Sciences, Westville Campus, University of KwaZulu-Natal, Durban, South Africa.

** Specialist Cardio-Thoracic Surgeon, St Augustine's Hospital, Chelmsford Medical Centre, Durban, KwaZulu Natal, South Africa.
} 
This study aimes to analyze the anatomical properties of the LCA (parameters such as branching and dominant patterns; length, diameter and the angle of division between its terminal branches) that may be of importance in the diagnosis and management of LCA diseases in a single series.

\section{MATERIAL AND METHOD}

Two hundred and thirty-two consecutive coronary angiograms obtained from the cardiac catheterization laboratory in the the eThekwini Municipality area of KwaZulu-Natal, South Africa were reviewed. In 62 angiograms, there was significant atherosclerotic lesions in the LCA, history of coronary bypass graft surgery and stent insertion. In addition, the LCA was absent in 19 angiograms and the AIA, Cx artery and a Ramus medianus artery (RM) (when present) originated directly from the left aortic sinus. These angiograms $(n=81)$ were excluded from the series that were analyzed. Therefore, a total of 151 coronary angiograms which consisted of 107 males and 44 females were analysed. The length, luminal diameter and angle of division of the LCA were measured. The dominant and branching patterns of the LCA were also recorded.

The LCA length was measured in each of the angiograms from its orifice (visualised by spillback of contrast medium into the aorta during selective injection) to its point of division into its terminal branches. Measurements were made in a single frame projection that shows the LCA and its point of branching clearly, in all patients. Correction for magnification was done by calibrating the projected size of the Judkins ${ }^{\circledR}$ catheter to its actual size. This was achieved by auto-calibrating the catheter on the software used for analyzing the angiographic images. This calibration ensured that the values recorded are the actual and not the magnified sizes of the coronary vessels seen on the screen. The projected radiological angle between the origins of the AIA and Cx artery (i.e. bifurcation angle) was measured in a single frame projection (Left Anterior Oblique, caudal view) that shows the LCA and its point of branching clearly. All statistical analyses were performed using the Statistical Package for the Social Sciences (SPSS) and a P value $\leq 0.05$ was considered significant.

The vessel giving off the posterior descending artery branch was defined as the dominant coronary artery. The branching of the LCA into two terminal branches viz. the AIA and $\mathrm{Cx}$ artery was classified as the bifurcation pattern. In the presence of an additional terminal branch (a RM), it was classified as either a trifurcation (for one RM) or quadrifurcation pattern (for two RMs). The RM was defined as a vessel that originated from the vertex of the angle between the AIA and Cx artery.

\section{RESULTS}

\section{LCA Morphology}

Brancing Patterns. The branching patterns of the LCA were recorded as 122/151 (80.8\%), 28/151 (18.5\%) and 1/151 $(0.7 \%)$ for bifurcation (Fig. 1), trifurcation (Fig. 2) and quadrifurcation patterns (Fig. 3), respectively.

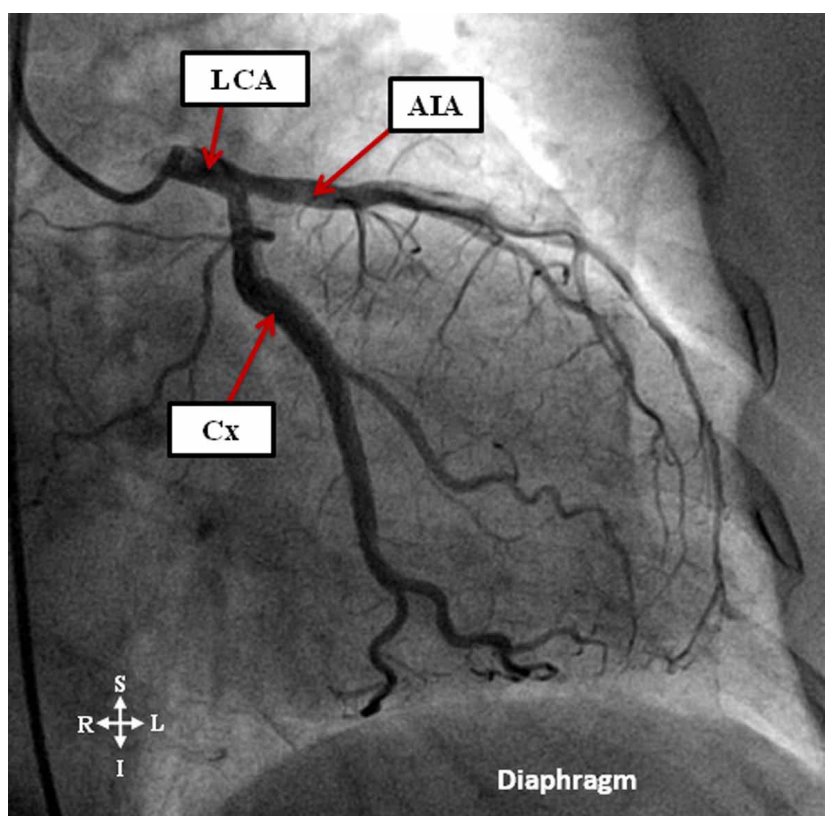

Fig. 1. Coronary angiogram in the right anterior oblique projection showing bifurcation of the into anterior interventricular artery (AIA) and circumflex (Cx) artery.

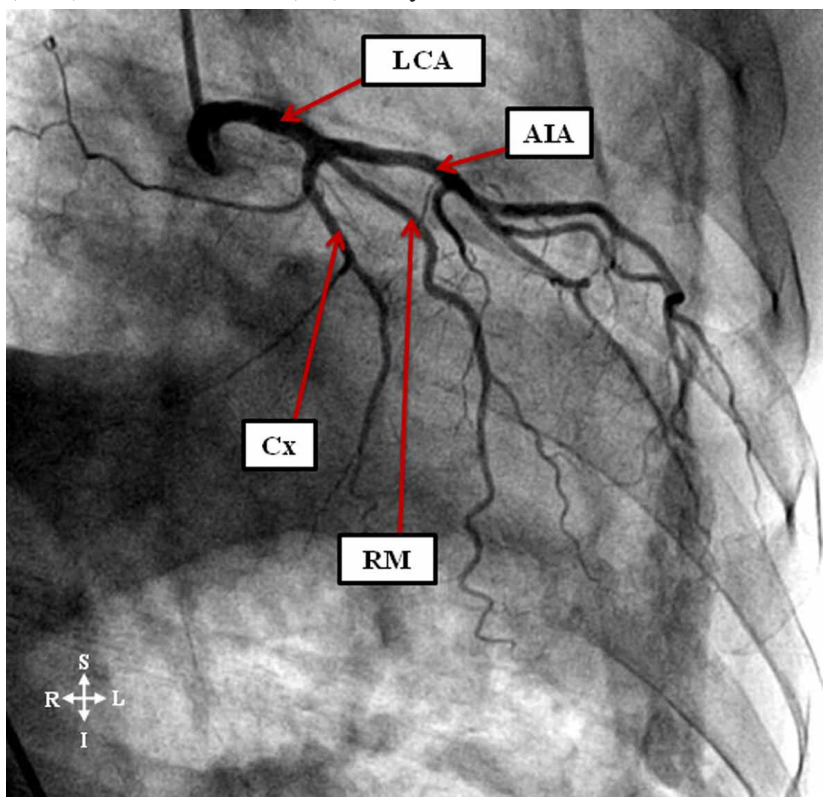

Fig. 2. Coronary angiogram in the right anterior oblique projection showing trifurcation of the into anterior interventricular artery (AIA), left circumflex (Cx) and a ramus medianus artery (RM). 


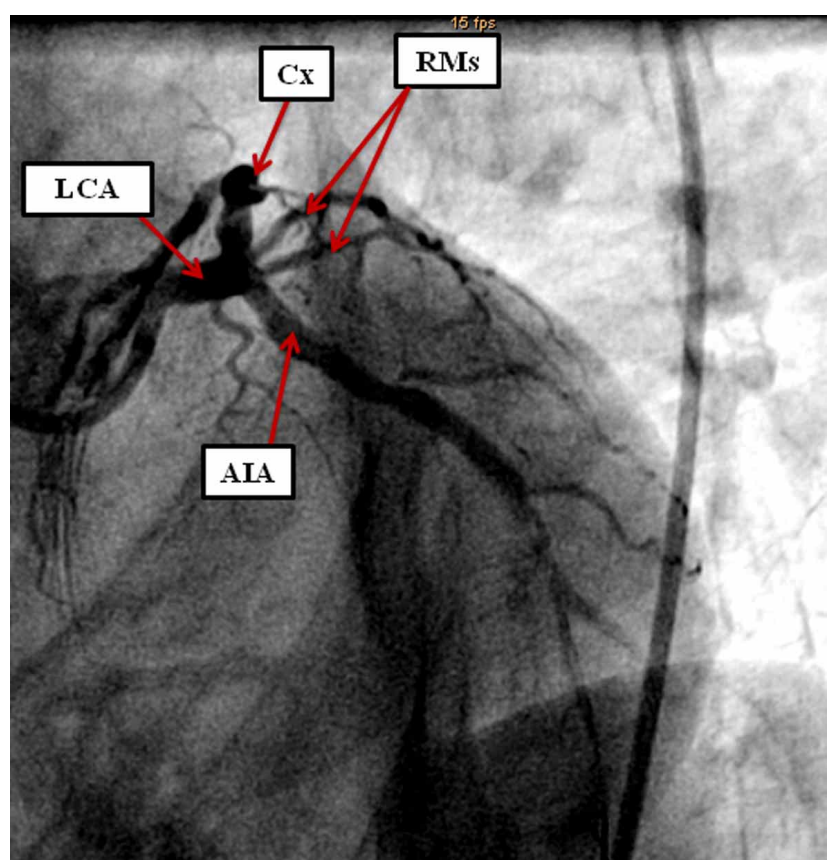

Fig. 3. Coronary angiogram in the left anterior oblique projection (caudal view) showing the quadrifurcation of the left coronary artery into anterior interventricular (AIA), circumflex (Cx) artery and two ramus medianus arteries (RMs).

Dominant Patterns. The dominant patterns of the LCA were $81.5 \%, 15.2 \%$ and $3.3 \%$ for right, left and co-dominant coronary arterial dominant patterns, respectively.

\section{LCA Mophometry}

Length of the left coronary artery. The mean length of the LCA in the coronary angiograms $(\mathrm{n}=151)$ analyzed was 10.4 $\pm 4.1 \mathrm{~mm}$ (range $2.8-23.9 \mathrm{~mm}$ ).

Sex. The mean lengths of the LCA were $10.3 \pm 4.1 \mathrm{~mm}$ (range $2.8-22.4 \mathrm{~mm}$ ) and $10.6 \pm 4.4 \mathrm{~mm}$ (range $3.4-23.9$ $\mathrm{mm}$ ) for males and females, respectively. There were no statistically significant difference between sexes $(\mathrm{p}=0.696)$.

Branching Patterns. The mean lengths of the LCA were $10.1 \pm 3.9 \mathrm{~mm}$ (range $2.8-23.9 \mathrm{~mm}$ ) and $11.4 \pm 5 \mathrm{~mm}$ (range $3.4-22.4 \mathrm{~mm}$ ) for bifurcation and trifurcation patterns of the LCA, respectively. The single specimen that presented with a quadrifurcation pattern had a length of $14.8 \mathrm{~mm}$. There were no statistically significant difference in the length of the LCA among the different branching patterns $(\mathrm{p}=0.196)$ (Table I).

Dominant Patterns. With regard to the coronary arterial dominance, the highest mean LCA length of $10.6 \pm 4.3 \mathrm{~mm}$ (range 2.8-23.9 mm) was recorded in the right dominant pattern, while left and co-dominant arterial patterns had mean lengths of $9.4 \pm 3.3 \mathrm{~mm}$ (range 3.4-15.4 mm) and 7.6 \pm 2.5 $\mathrm{mm}$ (range 3.4-10.1 mm), respectively. There were also no statistically significant difference in the length of the LCA among the different dominant patterns $(\mathrm{p}=0.138)$ (Table II).

Diameter of the left coronary artery. The mean diameter of the LCA in the angiograms $(\mathrm{n}=151)$ analyzed was $3.8 \pm$ $0.8 \mathrm{~mm}$ (range $2.1-6.5 \mathrm{~mm}$ ).

Sex. Males and females had an equal mean diameter of 3.8 $\pm 0.8 \mathrm{~mm}$ (range $2.1-6.5 \mathrm{~mm}$ ) and $3.8 \pm 0.7 \mathrm{~mm}$ (range 2.6 $-5.6 \mathrm{~mm})$, respectively

Brancing Patterns. The mean diameter of LCA in the bifurcation and trifurcation were $3.8 \pm 0.8 \mathrm{~mm}$ (range 2.1 $6.5 \mathrm{~mm}$ ) and $3.6 \pm 0.5 \mathrm{~mm}$ (range $2.7-4.6 \mathrm{~mm}$ ), respectively. The single specimen with a quadrifurcation pattern had a diameter of $5 \mathrm{~mm}$. There were no statistically significant difference in the diameter of the LCA among the different branching patterns $(\mathrm{p}=0.09)$ (Table I).

Dominant Patterns. In the coronary arterial dominant patterns, the mean diameters were $3.8 \pm 0.8 \mathrm{~mm}$ (range 2.1$6.5 \mathrm{~mm}$ ), $3.8 \pm 0.8 \mathrm{~mm}$ (range 2.3-4.7 $\mathrm{mm}$ ) and $4.1 \pm 0.6$ $\mathrm{mm}$ (range 3.4-4.8 $\mathrm{mm}$ ) for the right, left and co-dominant patterns, respectively. There were no statistically significant difference in the diameter of the LCA among the different dominant patterns $(\mathrm{p}=0.569)$ (Table II).

Angle of division of the left coronary artery. The mean angle of division between the two main branches (AIA and Cx artery) of the LCA for the angiograms was $86.2^{\circ} \pm 26.1^{\circ}$ (range $27^{\circ} \mathrm{O}-168.5^{\circ}$ ). A Pearson's analysis of non parametric correlation showed a positive correlation $(\mathrm{r}=0.257$; $\mathrm{P}=$ 0.001 ) between the length of the LCA and the angle of division of its terminal branches, with the longest LCAs having the largest angle of division.

Table I. Mean length, diameter and angle of division of the LCA in the branching patterns.

\begin{tabular}{lccccccc}
\hline \multirow{2}{*}{ Branching pattern } & \multicolumn{2}{c}{ Bifurcation (n=122) } & \multicolumn{2}{c}{ Trifurcation (n=28) } & \multirow{2}{*}{$\begin{array}{c}\text { Quadrifurcati } \\
\text { on }(\mathbf{n = 1})\end{array}$} & $\boldsymbol{p}$ value & Total (n=151) \\
\cline { 2 - 7 } & Mean (SD) & Min-Max & Mean (SD) & Min-Max & Mean (SD) \\
\hline Length (mm) & $10.1(3.9)$ & $2.8-23.9$ & $11.4(5)$ & $3.4-22.4$ & 14.8 & $\mathbf{0 . 1 9 6}$ & $\mathbf{1 0 . 4}(\mathbf{4 . 1})$ \\
Diameter (mm) & $3.8(0.8)$ & $2.1-6.5$ & $3.6(0.5)$ & $2.7-4.6$ & 5 & $\mathbf{0 . 0 9}$ & $\mathbf{3 . 8}(\mathbf{0 . 8})$ \\
Angle of division $\left({ }^{\circ}\right)$ & $81.3(23.2)$ & $27-148.6$ & $105.1(26.7)$ & $51.3-168.5$ & 153.8 & $\mathbf{0 . 0 0 0 1}$ & $\mathbf{8 6 . 2}(\mathbf{2 6 . 1})$ \\
\hline
\end{tabular}


AJAYI, N. O.; LAZARUS, L.; VANKER, E. A. \& SATYAPAL, K. S. Anatomic parameters of the left coronary artery: an angiographic study in a South African population. Int. J. Morphol., 31(4):1393-1398, 2013.

Table II. Mean length, diameter and angle of division of the LCA in the dominant patterns.

\begin{tabular}{|c|c|c|c|c|c|c|c|}
\hline \multirow{2}{*}{ Dominant pattern } & \multicolumn{2}{|c|}{ Right dominance $(\mathrm{n}=123)$} & \multicolumn{2}{|c|}{ Left dominance $(n=23)$} & \multicolumn{2}{|c|}{ Co-dominance $(n=5)$} & \multirow{2}{*}{$p$ value } \\
\hline & Mean (SD) & Min-Max & Mean (SD) & Min-Max & Mean (SD) & Min-Max & \\
\hline Length (mm) & $10.6(4.3)$ & $2.8-23.9$ & $9.4(3.3)$ & $3.4-15.4$ & $7.6(2.5)$ & $3.4-10.1$ & 0.138 \\
\hline Diameter $(\mathrm{mm})$ & $3.8(0.8)$ & $2.1-6.5$ & $3.8(0.8)$ & $2.3-4.7$ & $4.1(0.6)$ & $3.4-4.8$ & 0.569 \\
\hline Angle of division $\left({ }^{\circ}\right)$ & $86.4(26)$ & $27-168.5$ & $85.4(23.2)$ & $43.4-134.3$ & $85.6(44)$ & $35-148.6$ & 0.985 \\
\hline
\end{tabular}

Sex. In males, the mean angle of division was recorded as $88 \mathrm{o} \pm 27.2 \mathrm{o}$ (range $27 \mathrm{o}-168.5 \mathrm{o}$ ) and females had a lower value of $81.7 \mathrm{o} \pm 22.98 \mathrm{o}$ (range $46.5 \mathrm{o}-136.3 \mathrm{o}$ ). There were no statistically significant difference between sexes $(\mathrm{p}=0.153)$.

Branching Pattern. The mean angle of division of the LCA for the bifurcation and trifurcation patterns were 81.3o \pm $23.2 \mathrm{o}$ (range $27 \mathrm{o}-148.6 \mathrm{o}$ ) and $105.1 \mathrm{o} \pm 26.7 \mathrm{o}$ (range $51.34 \mathrm{o}$ -168.50 ), respectively. The single specimen that presented with a quadrifurcation pattern had an angle of division of 153.80. There was a statistically significant difference in the angle of division of the LCA among the different branching patterns $(\mathrm{p}=0.0001)$ (Table I).

Dominant Pattern. The mean angle of division of the LCA in the right, left and co-dominant patterns were 86.40 \pm 260 (range 27o-168.5o), 85.4o $\pm 23.2 \mathrm{o}$ (range $43.4 \mathrm{o}-134.3 \mathrm{o}$ ) and $85.6 \mathrm{o} \pm 44 \mathrm{o}$ (range $35 \mathrm{o}-148.6 \mathrm{o}$ ), respectively. There was no significant difference in the length of the LCA among the different dominant patterns $(\mathrm{p}=0.985)$ (Table II).

\section{DISCUSSION}

In the last few decades, several studies evaluated the morphology and morphometry of the coronary arteries (Vieweg et al.; Dodge et al.; Cavalcanti et al., 2003; Kaimkhani et al., 2004; Reig \& Petit; Zeina et al., 2007; Christensen et al., 2010). The length of the LCA is commonly considered to be between 5-15 mm long (Reig and Petit, 2004) and rarely longer than $20 \mathrm{~mm}$ in adults (Loukas et $a l$.$) . The mean length of LCA has been estimated in several$ studies both radiologically and at autopsy. In angiography, it ranges between $9.5 \mathrm{~mm}$ (Fox et al.) and $12.8 \mathrm{~mm}$ (Lewis et al., 1970) and at autopsy, it is between $5.5 \mathrm{~mm}$ (Fox et al.) and $11 \mathrm{~mm}$ (Gazetopoulos et al., 1976b), while in computer tomographic studies, it is between $9.9 \mathrm{~mm}$ (Christensen et al.) and $10.5 \mathrm{~mm}$ (Zeina et al.). The lower value reported at autopsy may be as a result of post-mortem changes as compared to investigation done in living subjects.

Using the criteria of extreme values, Reig \& Petit classified the LCA as 'short' if it is $\leq 5 \mathrm{~mm}$ and 'long' if it is $>15 \mathrm{~mm}$. In the present study, the LCA length was recorded
$<5 \mathrm{~mm}$ in eight (5.3\%) and > $15 \mathrm{~mm}$ in $16(10.6 \%)$ of the angiograms. Fox et al. noted that the early bifurcation of the LCA may cause peri-operative occlusion of its main branch by a balloon-tipped perfusion cannula with resultant myocardial infarction, and in such cases, separate cannulation of the AIA and $\mathrm{Cx}$ artery is recommended. Therefore, 5.3\% of the sample population in the present study could be at risk of iatrogenic myocardial ischemia. The mean length of LCA was recorded as $10.4 \pm 4.1 \mathrm{~mm}$ in the present study, which is within the values of $9.5 \mathrm{~mm}$ and $12.8 \mathrm{~mm}$ in similar angiographic studies from the literature reviewed.

From the literature reviewed, there are no reports comparing the mean length of the LCA between males and females in adults. There was no statistically significant difference in the mean length of the LCA recorded for males $(10.3 \pm 4.1 \mathrm{~mm})$ and females $(10.6 \pm 4.4 \mathrm{~mm})$ in the present study. In the different branching patterns, the mean length of the LCA in the bifurcation and trifurcation patterns were $10.1 \mathrm{~mm}$ and $11.4 \mathrm{~mm}$ for the bifurcation and trifurcation of the LCA, respectively. The single specimen that presented with a quadrifurcation pattern had a length of $14.8 \mathrm{~mm}$. The findings of this study showed that in the trifurcation pattern, the LCA has a longer mean length than the bifurcation pattern. The present study confirms the findings of Nikolic et al. (2011) who stated that the mean length of LCA is longer in trifurcation than in bifurcation pattern. However, it could not validate the association between the lengths of the LCA and its branching pattern due to the small sample size of the quadrifurcation pattern in this study. Furthermore, this finding may therefore suggest that a higher number of LCA branches is associated with longer LCA length.

The present investigation recorded the highest mean length of $10.5 \pm 4.3 \mathrm{~mm}$ in the right dominant pattern, while left and co-dominant arterial patterns had mean lengths of $9.4 \pm 3.3$ $\mathrm{mm}$ and $7.6 \pm 2.5 \mathrm{~mm}$, respectively. The results of this study, therefore confirmed the association of shorter LCA with the left coronary arterial dominance as reported by Kronzon et al. (1974), Saltissi et al. and Kurjia et al. (1986). However, it was contrary to the observation of Abedin \& Goldberg (1978) who reported no difference in the mean length of the LCA between right and left coronary arterial dominant patterns. Left coronary arterial dominance associated with short LCA was reported to be associated with coronary artery disease (Kurjia et al.). 
The mean internal diameter of the LCA was found to be $3.8 \mathrm{~mm}$, which falls within the values of $3.6 \mathrm{~mm}$ and 4.9 $\mathrm{mm}$ reported in previous studies. In this study, males and females had the same mean diameter of $3.8 \pm 0.8 \mathrm{~mm}$ and $3.8 \pm 0.7 \mathrm{~mm}$, respectively, which was contrary to the finding of Dodge et al., who reported that males have larger diameters than females. It has been reported that patients with small vessels are at a higher risk of having an adverse outcome following coronary stent placement due to a higher incidence of re-stenosis (Elezi et al., 1998). In coronary artery bypass surgery, the most important factor in predicting the success of the operation is the size of the vessel to which the bypass is anastomosed (Abrams, 1982).

The mean angle of division between the two main branches (AIA and Cx artery) of the LCA was 86.20 \pm 26.10 . This is similar to the value $\left(86.7^{\circ}\right)$ reported by Reig \& Petit but differs from a computer tomographic study by Christensen et al., who reported a mean angle of 69.3o. The mean angle of division in the trifurcation pattern of 105.10 (range $51.3^{\circ}-168.5^{\circ}$ ) was significantly larger than the mean angle of $81.3^{\circ}$ (range $27^{\circ}-148.6^{\circ}$ ) recorded for the bifurcation of the LCA $(\mathrm{p}=0.0001)$. Therefore, the result of this study reports a significant increase in the angle of division of the LCA in the presence of RM artery.

The result of this investigation revealed a significant correlation between the length of the LCA and its angle of division. The positive correlation $(\mathrm{r}=0.257$; $\mathrm{p}=0.001)$ between length $(10.4 \mathrm{~mm})$ and angle of division $\left(86.2^{\circ} \pm\right.$ $26.1^{\circ}$ ) indicated that the longer the LCA, the greater the angle of division. The result of this study corroborated the findings of Reig \& Petit and Christensen et al., who also reported that the longer the length of the LCA, the wider the angle of its division. However, there was no correlation between the length of the LCA and its diameter; it also showed no correlation between the diameter of the LCA and its angle of division. According to Saltissi et al., the proximal location of atherosclerotic lesions in the branches of the LCA is associated with wider angle of division of the LCA.Therefore, the wider the angle of division, the greater the possibility of atherosclerotic lesions distribution in the proximal segment of LCA branches, which may result in myocardial ischemia and infarction.

\section{CONCLUSION}

The understanding of the LCA anatomy is an issue of clinical importance due to the extensive use of radiographic images for diagnostic and interventional purposes. The present study found a significant correlation between the length of the LCA and its angle of division. A detailed knowledge of the LCA anatomy and its variations is of clinical importance in the management of patients with coronary arterial diseases.

AJAYI, N. O.; LAZARUS, L.; VANKER, E. A. \& SATYAPAL, K. S. Parámetros anatómicos de la arteria coronaria izquierda: estudio angiográfico en una población sudafricana. Int. J. Morphol., 31(4):1393-1398, 2013.

RESUMEN: La comprensión anatómica de la arteria coronaria izquierda (ACI) es importante para el diagnóstico e intervención terapéutica en el tratamiento de enfermedades arteriales coronarias. Este estudio angiográfico tuvo como objetivo documentar los parámetros de la ACI que pueden ser de importancia en el diagnóstico y tratamiento de enfermedades de las arterias coronarias. Se realizó el análisis de 151 angiografías coronarias obtenidas del laboratorio de cateterización cardíaca en el área del Municipio eThekwini de KwaZuluNatal, Sudáfrica. La longitud y diámetro promedio de la ACI fueron 10,4 $\pm 4,1 \mathrm{~mm}$ (rango 2,8 a 23,9 mm) y 3,8 $\pm 0,8 \mathrm{~mm}$ (rango de 2,1 hasta $6,5 \mathrm{~mm}$ ), respectivamente. El ángulo medio de la división entre las dos ramas principales fue $86,2^{\circ} \pm 26,1^{\circ}\left(\operatorname{rango} 27^{\circ}-168,5^{\circ}\right.$ ). Hubo una correlación positiva entre la longitud y el ángulo de división de la ACI, donde las ACI más largas tuvieron un ángulo de división más grande. Los patrones de ramificación de la ACI fueron porcentualmente 80,8\%, 18,5\% y 0,7\% para bifurcación, trifurcación y quadrifurcación, respectivamente. La dominancia arterial coronaria fue del 81,5\%, 15,2\% y 3,3\% para la derecha, izquierda y en codominio, respectivamente. Este estudio corrobora hallazgos anteriores en que cuanto mayor sea la longitud, mayor será el ángulo de la división de ACI. Un amplio ángulo de la división de la ACI, la forma y la disposición del tracto proximal de las ramas de la ACI pueden afectar el flujo, interferir con el despliegue apropiado de los stents o predisponer a las lesiones ateroscleróticas tempranas.

PALABRAS CLAVE: Arterias coronarias; Arteria coronaria izquierda; Morfología; Morfometría; Dominancia coronaria.

\section{REFERENCES}

Abedin, Z. \& Goldberg, J. Origin and Length of Left Main Coronary Artery: Its Relation to Height, Weight, Sex, Age, Pattern of Coronary Distribution, and Presence or Absence of Coronary Artery Disease. Cathet.
Cardiovasc. Diagn., 4(3):335-40, 1978.

Abrams, H. L. Coronary Arteriography: Pathologic and Prognostic Implications. AJR Am. J. Roentgenol., 139(1):1-18, July, 1982. 
Cavalcanti, J. S.; de Melo, N. C. \& de Vasconcelos, R. S. Morphometric and Topographic Study of Coronary Ostia. Arq. Bras. Cardiol., 81(4):359-62, 2003.

Christensen, K. N.; Harris, S. R.; Froemming, A. T.; Brinjikji, W.; Araoz, P.; Asirvatham, S. J. \& Lachman, N. Anatomic assessment of the bifurcation of the left main coronary artery using multidetector computed tomography. Surg. Radiol. Anat., 32(10):903-9, 2010.

Dodge, J. T. Jr.; Brown, B. G.; Bolson, E. L. \& Dodge, H. T. Lumen diameter of normal human coronary arteries. Influence of age, sex, anatomic variation, and left ventricular hypertrophy or dilation. Circulation, 86(1):232-46, 1992.

Elezi, S.; Kastrati, A.; Neumann, F.; Hadamitzky, M.; Dirschinger, J. \& Schömig, A. Vessel Size and Long-Term Outcome After Coronary Stent Placement. Circulation, 98(18):1875-80, 1998.

Fazliogullari, Z.; Karabulut, A. K.; UnverDogan, N. \& Uysal, I. Coronary artery variations and median artery in Turkish cadaver hearts. Singapore Med. J., 51(10):775-80, 2010.

Fox, C.; Davies, M. J. \& Webb-Peploe, M. M. Length of left main coronary artery. Br. Heart J., 35(8):796-8, 1973.

Gazetopoulos, N.; Ioannnidis, P. J.; Marselos, A.; Kelekis, D.; Lolas, C.; Avgoustakis, D. \& Tountas, C. Length of main left coronary artery in relation to atherosclerosis of its branches A coronary arteriographic study. Br. Heart J., 38(2):180-5, 1976a.

Gazetopoulos, N.; Ioannidis, P. J.; Karydis, C.; Lolas, C.; Kiriakou, K. \& Tountas, C. Short left coronary artery trunk as a risk factor in the development of coronary atherosclerosis Pathological study. Br. Heart J., 38(11):1160-5, 1976b.

Kaimkhani, Z.; Alim, M. \& Faruqui, A. M. A. Coronary artery diameter in a cohort of adult Pakistani population. J. Pak. Med. Assoc., 54(5):259-61, 2004.

Kurjia, H. Z.; Chaudhry, M. S. \& Olson, T. R. Coronary Artery Variation in a Native Iraqi Population. Cathet. Cardiovasc. Diagn., 12(6):38690, 1986.

Kronzon, I.; Deutsch, P. \& Glassman, E. Length of the left main coronary artery: Its relation to the pattern of coronary arterial distribution. Am. J. Cardiol., 34(7):787-9, 1974.

Leung, W. H.; Stadius, M. L. \& Alderman, E. L. Determinants of normal coronary artery dimensions in humans. Circulation, 84(6):2294-306, 1991.

Lewis, C. M.; Dagenais, G. R.; Friesinger, G. C. \& Ross, R. S. Coronary arteriographic appearances in patients with left bundle-branch block. Circulation, 41(2):299-307, 1970.

Lip, G. Y.; Rathore, V. S.; Katira, R.; Watson, R. D. \& Singh, S. P. Do Indo-Asians have smaller coronary arteries? Postgrad. Med. J., 75(886):463-6, 1999.
Loukas, M.; Groat, C.; Khangura, R.; Owens, D. G. \& Anderson, R. $\mathrm{H}$. The Normal and Abnormal Anatomy of the Coronary Arteries. Clin. Anat., 22(1):114-28, 2009.

Muriago, M.; Sheppard, M. N.; Ho, S. Y. \& Anderson, R. H. Location of the Coronary Arterial Orifices in the Normal Heart. Clin. Anat., 10(5):297-302, 1997.

Nikolic, V.; Blagojevic, Z.; Stijak, L.; Malis, M.; Parapid, G. T.; Stankovic, G.; Spasojevic, G. \& Filipovic, B. The Third Branch of the Main Trunk of the Left Coronary Artery in Cercopithecusaethiopssabaeus. Is the Nonhuman Primate Model Appropriate? Anat. Rec. (Haboken), 294(9):1506-10, 2011.

Reig, J. \& Petit, M. Main Trunk of the Left Coronary Artery: Anatomic Study of the Parameters of Clinical Interest. Clin. Anat., 17(1):6-13, 2004.

Saikrishna, C.; Talwar, S.; Gulati, G. \& Kumar, A. S. Normal coronary artery dimensions in Indians. IJTCVS, 22:159-64, 2006.

Saltissi, S.; Webb-Peploe, M. M. \& Coltar, D. J. Effect of variation in coronary artery anatomy on distribution of stenotic lesions. Br. Heart J., 42(2):186-91, 1979.

Vieweg, W. V.; Alpert, J. S. \& Hagan, A. D. Caliber and distribution of normal coronary arterial anatomy. Cathet. Cardiovasc. Diagn., 2(3):269-80, 1976.

Vilallonga, J. R. Anatomical variations of the coronary arteries: The most frequent variations. Eur. J. Anat., 7(Suppl. 1):29-41, 2003.

Zeina, A. R.; Rosenschein, U. \& Barmeir, E. Dimensions and anatomic variations of left main coronary artery in normal population: multidetector computed tomography assessment. Coron. Artery. Dis., 18(6):477-82, 2007.

Zindrou, D.; Taylor, K. M. \& Bagger, J. P. Coronary artery size and disease in UK South Asian and Caucasian men. Eur. J. Cardiothorac. Surg., 29(4):492-5, 2006.

\section{Correspondence to:}

Prof. K. S. Satyapal

Department of Clinical Anatomy

School of Laboratory Medicine and Medical Sciences

College of Health Sciences, Westville Campus

University of KwaZulu-Natal

Private Bag X54001

Durban, 4000

SOUTH AFRICA

\section{Email: satyapalk@ukzn.ac.za}

Received: 11-10-2013

Accepted: 28-10-2013 